\title{
Comparative Effects of Recombinant Acid Sphingomyelinase Administration by Different Routes in Niemann-Pick Disease Mice
}

\author{
J ae-Sung $B A E{ }^{1)}$, Kwang-HoJ $A N G^{1)}$, Edward H. SCHUCHMAN ${ }^{2)}$ and Hee Kyung J IN ${ }^{1)}$ \\ ${ }^{1)}$ Department of Laboratory Animal Medicine and Department of Surgery, College of Veterinary Medicine, \\ Kyungpook National University, Daegu, Korea 702-701, and ${ }^{2}$ Department of Human Genetics, \\ Mount Sinai School of Medicine, New York, NY 10029, USA
}

\begin{abstract}
An inherited deficiency of acid sphingomyelinase (ASM) activity results in the Type $A$ and $B$ forms of Niemann-Pick disease (NPD). The aim of this study was to evaluate the effects of recombinant human ASM (rhASM) replacement therapy on the mouse model, by comparing different routes of administration. Eight NPD mice received rhASM via an intravenous injection (IV) administered at a dose of $1 \mathrm{mg} / \mathrm{kg}$ and another group of 8 NPD mice received the same dose by subcutaneous injection (SC). The plasma levels of ASM activity in intravenously administered mice were significantly elevated immediately after injection. In contrast, in the subcutaneously injected mice, the level of ASM activity was maximal $6 \mathrm{~h}$ after injection. The levels of ASM activity in both groups had declined substantially by 2 days after injection. It was concluded that rhASM administered by subcutaneous injection is completely absorbed, and offers a similar efficacy to intravenously administered recombinant enzyme.
\end{abstract}

Key words: Acid sphingomyelinase, enzyme replacement therapy, lysosomal storage disorder

\section{Introduction}

Types A and B Niemann-Pick disease are two clinically distinct forms of an inherited lysosomal storage disorder resulting from the deficient activity of acid sphingomyelinase (ASM; sphingomyelin phosphodiesterase; E.C. 3.1.2.14) [1]. ASM is responsible for hydrolyzing the lipid, sphingomyelin (SPM), to ceramide and phosphocholine, and both forms of Niemann-Pick disease are characterized by extensive lipid storage in various cells and tissues.
Enzyme replacement therapy was first suggested as an approach to the treatment of lysosomal storage disorders over thirty years ago [2]. During the past decade the isolation of genes encoding most lysosomal enzymes and the development of expression systems that produce large quantities of recombinant proteins has led to the successful treatment of several lysosomal storage diseases in animal models, providing "proof of principle" for this approach [2, 3]. In addition, enzyme therapy has become available for three human lysosomal storage diseases, Type 1 Gaucher disease, Fabry

(Received 10 February 2004 / Accepted 4 June 2004)

Address corresponding: H.K. Jin, College of Veterinary Medicine, Kyungpook National University, Daegu, Korea $702-701$ 
disease, and mucopolysaccharidosis type 1 [4-6], and clinical trials are underway for several other disorders [7-10]. However, enzyme therapy is limited by short enzyme half-life and thus requires continuous intravenous (IV) infusion. Thrombosis, paradoxical embolism, and treatment interruptions due to occlusion and logistical difficulty have all been reported with intravenous administration. Therefore, as an alternative, subcutaneous (SC) administration has been proposed [11].

The goal of the current study was to evaluate the efficacy of rhASM administered either IV or SC directly and to examine the pharmacokinetics of the active metabolite in a NPD mouse model. The data support the efficacy of SC enzyme replacement therapy using rhASM and may present a viable alternative to current enzyme replacement therapy for NPD patients.

\section{Materials and Methods}

\section{Animals}

The NPD mouse model was created by gene targeting as described previously [12]. The NPD knockout mouse has been used to study the pathogenesis and treatment of type A and B NPD [13]. Affected mice have no detectable ASM activity, but develop normally until $\sim 8$ weeks of age, when ataxia and mild tremors become noticeable. The disease then follows a neurodegenerative course that leads to death between 6 and 8 months of age. Characteristic lipid-laden foam cells (NPD cells) are found in most major organs, associated with elevated sphingomyelin levels. Affected mice can be distinguished from normal animals using a PCR-based assay [12]. The animals in our study were maintained on a $12 \mathrm{~h}$ light/dark cycle with water $\mathrm{ad}$ libitum and Purina rodent chow 5001. All animals were used in compliance with the Guideline for the Care and Use of Laboratory Animals, Mount Sinai School of Medicine.

\section{Enzyme administration}

Two groups of test animals were injected with purified recombinant human acid sphingomyelinase (rhASM) $(1.4 \mathrm{mg} / \mathrm{ml}$, GENZYME). The doses of $1 \mathrm{mg}$ rhASM/kg of mouse body weight were administered by IV and SC injection with a Bioinjector (BIOJECT ${ }^{\circledR}$, Portland, OR) into 5-month-old NPD mice (8 mice each per group). Plasma was taken at 0, 5, 10, $30 \mathrm{~min}, 1,2$,
4, $6 \mathrm{~h}$ and 1, 2, 3, 4, 5 days after injection for biochemical analyses. Mice received injections every other day for 1 week ( 3 injections) and were sacrificed $48 \mathrm{~h}$ after the last injection to assess their tissue ASM activity and SPM content.

\section{ASM activity and protein assays}

The ASM activity was determined as previously described [14, 15]. A fluorescence-based, high performance liquid chromatography method was used to measure ASM activity in macrophage lysates. Briefly, equal volumes of cell lysates (prepared by 3 cycles of freeze-thaw in $0.01 \mathrm{M}$ Tris- $\mathrm{HCl}$ buffer, $\mathrm{pH}$ 7.0, containing $0.25 \%$ Triton $\mathrm{X}-100$ ) and $0.2 \mathrm{M}$ BODIPY ${ }^{\circledR}$-labeled $\mathrm{C}_{12}$-sphingomyelin (Molecular Probes, Eugene, OR) diluted in assay buffer $(0.1 \mathrm{M}$ sodium acetate, $\mathrm{pH} 5.0$, containing $0.1 \mathrm{mM} \mathrm{ZnCl}_{2}$, and $0.5 \%$ Triton $\mathrm{X}-100$ ), were incubated at $37^{\circ} \mathrm{C}$ for 60 min. The reaction was stopped by the addition of ethanol, and the hydrolytic product (BODIPY ${ }^{\circledR}$ $\mathrm{C}_{12}$-ceramide) was detected and quantified by chromatographic analysis using a reverse phase column (Aquasil C-18, Keystone Scientific Inc., St. Marys, PA). Total protein was determined using the Bio-Rad protein assay kit according to the manufacturer's instructions.

\section{Tissue processing and lysenin immunostaining}

At $48 \mathrm{~h}$ after the last injection, injected animals and control littermates were anesthetized with avertin and sacrificed by cardiac perfusion. After post-fixed tissues were cryoprotected in $30 \%$ sucrose, they were cut into $15 \mu \mathrm{m}$ coronal sections using a cryostat. Frozen sections were treated with blocking buffer (PBS, pH 7.4 , containing $1 \%(\mathrm{w} / \mathrm{v}) \mathrm{BSA}$ ) for $1 \mathrm{~h}$. The slides were then incubated with $1 \mu \mathrm{g} / \mathrm{ml}$ lysenin, a sphingomyelin-specific binding protein [16] in 1\% BSA-PBS for $2 \mathrm{~h}$, washed with $1 \%$ BSA-PBS, and then incubated with anti-lysenin antiserum (1:1000 dilution in blocking buffer) for $1 \mathrm{~h}$. The slides were washed in $1 \%$ BSA-PBS and incubated with Alexa Fluor 568-conjugated anti-rabbit IgG (Molecular Probe, Eugene, OR) for $1 \mathrm{~h}$. Nuclei were counter-stained by mounting sections under $1.5 \mathrm{~mm}$ thick coverslips in Vectashield with DAPI. The sections were then analyzed using a Nikon Eclipse E800 fluorescence microscope. 


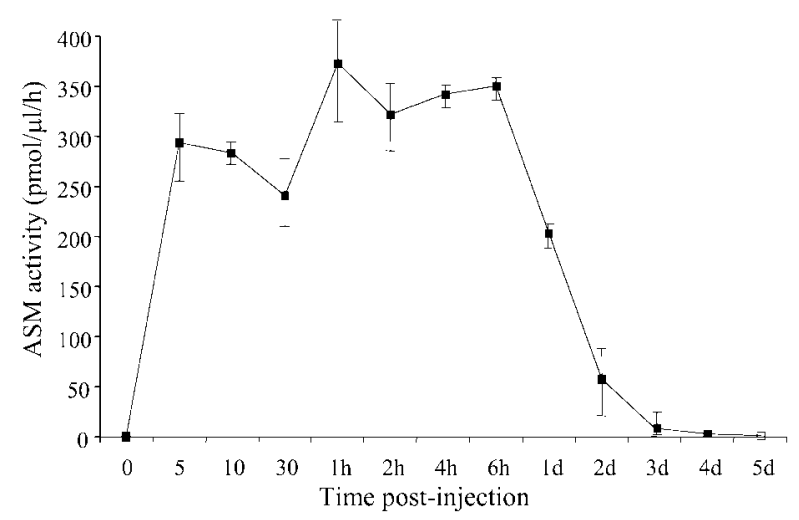

Fig. 1. ASM activities in the plasma of rhASM treated NPD mice after IV injection. Data are expressed as mean \pm $\operatorname{SEM}(n=8)$.

\section{Results}

IV or SC administration of rhASM gave rise to comparable ASM activities in plasma of NPD mice

The levels of ASM activity in IV injected mice elevated significantly immediately after injection (Fig. 1). In contrast, the levels of ASM activity in SC injected mice were maximal $6 \mathrm{~h}$ after injection (Fig. 2). Thereafter, the level of ASM activity in SC injected mice declined, substantially 2 days after injection.

Effect of the IV or SC administration on ASM activity in various tissues

NPD mice received injections of $\mathrm{rhASM}(1 \mathrm{mg} / \mathrm{kg})$ every other day for 1 week and were sacrificed $48 \mathrm{~h}$ after the last injection to assess their tissue ASM activity. The level of ASM activity was increased in the livers of IV injected NPD mice, whereas it was increased in the spleen, lungs, hearts, and kidneys of SC injected NPD mice (Fig. 3). The level of ASM activity was increased in the cerebellums of SC injected NPD mice (Fig. 3), however, analysis of brain sections from the treated NPD mice revealed massive Purkinje cell drop-out equivalent to that observed in non-treated NPD mice (data not shown), suggesting that the injected rhASM did not cross the blood-brain barrier to a significant degree.

Sphingomyelin levels in the spleen

Representative tissue sections from the spleen of rhASM treated mice and non-treated NPD mice are

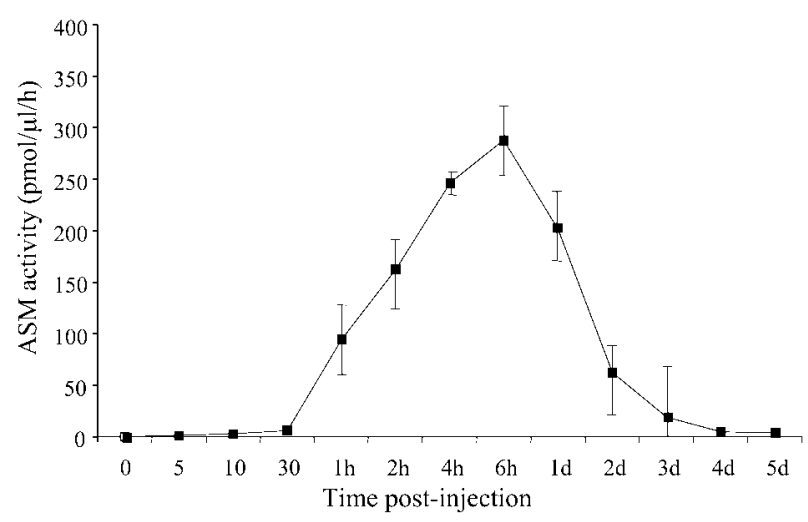

Fig. 2. ASM activities in the plasma of rhASM treated NPD mice after SC injection. Data are expressed as mean \pm SEM $(n=8)$.

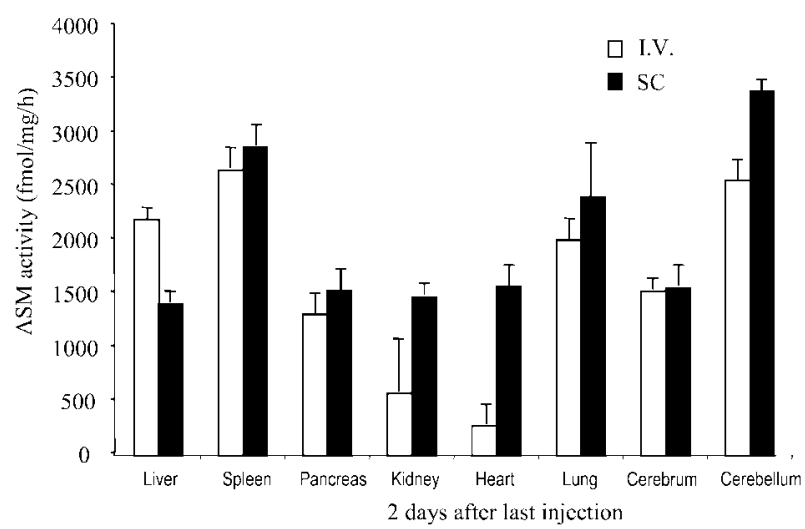

Fig. 3. ASM activities in tissues of rhASM treated NPD mice at 2 days after last injection, in the IV injected (open bar) and SC injected (closed bar) NPD mice. Data are expressed as mean $\pm \operatorname{SEM}(n=8)$.

shown in Fig. 4. We used lysenin, a sphingomyelinspecific binding protein, to assess sphingomyelin storage in the spleen sections from rhASM treated mice. As shown Fig. 4, lysenin staining in IV and SC injected NPD mice were slightly weaker compared with those tissues from non-treated NPD mice.

\section{Discussion}

In recent years, significant efforts have been devoted to the evaluation of enzyme replacement treatment for lysosomal storage diseases. ASM-deficient NPD is considered an excellent candidate for enzyme replacement therapy, particularly for patients without primary neu- 

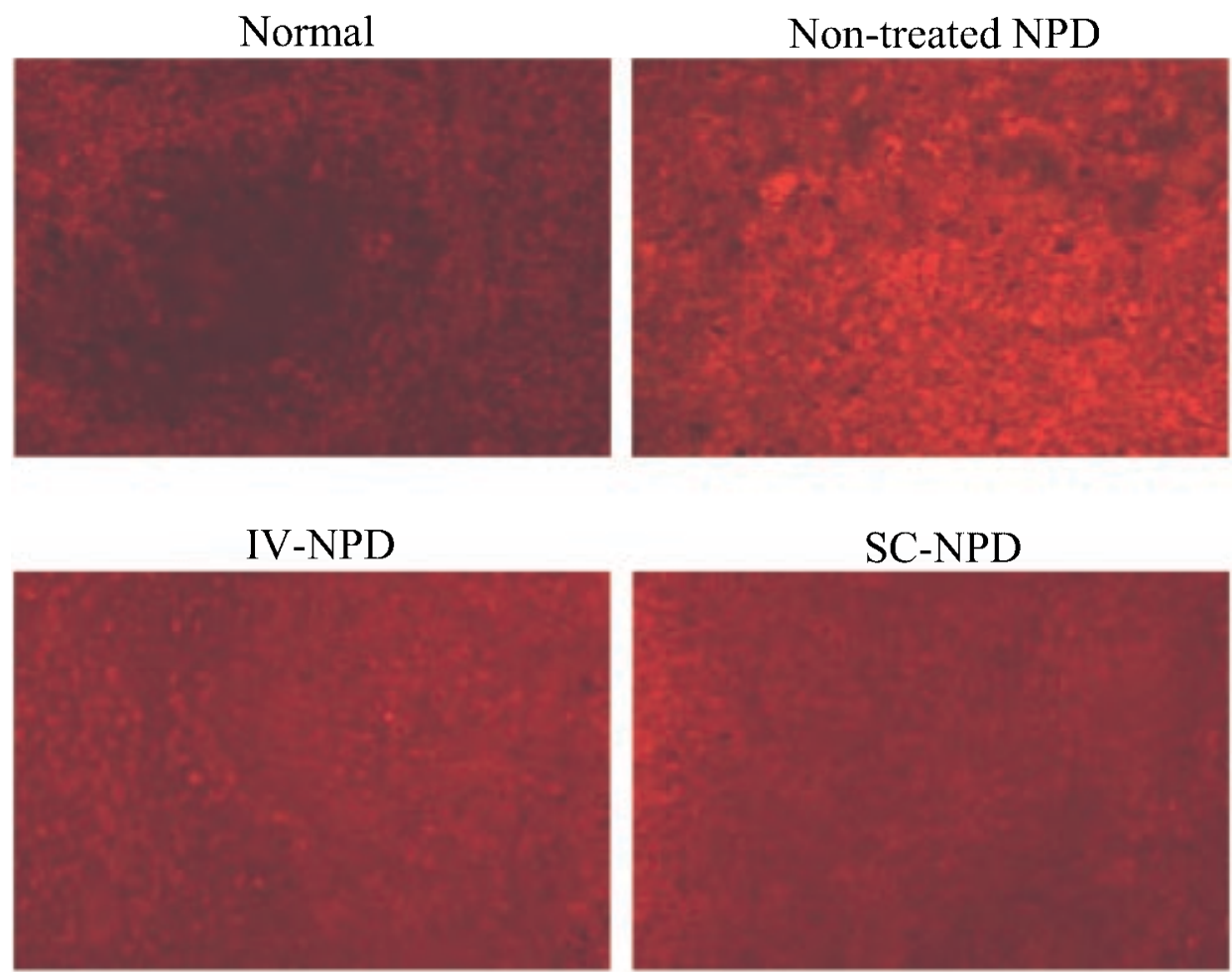

Fig. 4. Lysenin staining of spleen sections from the representative rhASM IV injected NPD, rhASM SC injected NPD, non-treated NPD, and normal control mice at 2 days after last injection. Original magnification $\times 40$.

rological involvement [1]. Previous studies have shown that intravenous injection of "complex" type rhASM obtained from Chinese hamster ovary cells into NPD mice reduced sphingomyelin storage in various visceral organs, including the liver, spleen and heart, and to a less degree, in the lung $[17,18]$. However, the treatment is limited by the very short half-life of continuous IV infusion and interrupted by serious problems with the methodology; therefore, subcutaneous administration has been proposed.

Figures 1 and 2 show that IV or SC administration of rhASM gives rise to comparable ASM activities in plasma of NPD mice. The levels of ASM activity in IV injected mice were significantly elevated immediately after injection. In contrast, the levels of ASM activity were maximal in SC injected mice $6 \mathrm{~h}$ after injection. The levels of ASM activity in both groups decreased, substantially 2 days after injection. NPD mice were successfully administered with rhASM (1 $\mathrm{mg} / \mathrm{kg}$ ) via IV and SC routes every other day for 1 week, and were sacrificed $48 \mathrm{~h}$ after the last injection to assess their tissue ASM activity. Figure 3 shows that levels of ASM activity were increased in the livers of IV injected NPD mice, whereas the levels of ASM activity were increased in the spleen, lungs, cerebellums, hearts, and kidneys of SC injected NPD mice. We used lysenin to assess sphingomyelin storage in the spleen sections from rhASM treated mice. As shown in Fig. 4, the amount of lysenin staining in IV and SC injected NPD mice was slightly decreased compared with those tissues from non-treated NPD mice. The rhASM enzyme replacement therapy for the NPD mice led to improved storage in visceral organs without detectable neurological changes.

The present results have provided important information for the future development of enzyme replacement therapy, and SC infusion offers a similar efficacy of rhASM enzyme replacement therapy as IV infusion. This represents a far superior method of treatment for confused patients and in cases which have difficulty with IV puncture. 


\section{Acknowledgments}

The authors thank J.K. Lee, S.I. Kim and H.B. Yoon for technical assistance. Thanks are also due to Dr. J. Carter, Department of Psychiatry and Behavioural Sciences, University College, London for helping with the preparation of this manuscript. This research was supported by Kyungpook National University Research Fund, 2003.

\section{References}

1. Schuchman, E.H. and Desnick, R.J. 2001. Niemann-Pick disease type A and B: acid-sphingomyelinase deficiencies. pp. 3589-3610. In: The metabolic and molecular bases of inherited disease. (Scriver, C.R., Beaudet, A.L., Sly, W.S. and Valle, D. ed) McGraw-Hill. New York, New York.

2. Ioannou, Y.A., Zeidner, K.M., Gordon, R.E., and Desnick, R.J. 2001. Fabry disease: preclinical studies demonstrate the effectiveness of alpha-galactosidase A replacement in enzyme-deficient mice. Am. J. Hum. Genet. 68: 14-25.

3. Vogler, C., Barker, J., Sands, M.S., Levy, B., Galvin, N., and Sly, W.S. 2001. Murine mucopolysaccharidosis VIL: impact of therapies on the phenotype, clinical course, and pathology in a model of a lysosomal storage disease. Pediatr. Dev. Pathol. 4: 421-433.

4. Desnick, R.J. 2001. Enzyme replacement and beyond. $J$. Inherit. Metab. Dis. 24: 251-265.

5. Kakkis, E.D., Muenzer, J., Tiller, G.E., Waber, L., Belmont, J., Passage, M., Izykowski, B., Phillips, J., Doroshow, R., Walot, I., Hoft, R., and Neufeld, E.F. 2001. EnzymeReplacement Therapy in Mucopolysaccharidosis I. N. Engl. J. Med. 18: 182-188.

6. van den Hout, H., Reuser, A., Vulto, A.G., Loone, M.C., Cromme-Dijkhuis, A., and Van der Ploeg, A.T. 2000. Recombinant human $\alpha$-glucosidase from rabbit milk in Pompe patients. Lancet 29: 397-398.

7. Wraith, J.E. 2001. Enzyme replacement therapy in mucopolysaccharidosis type I: Progress and emerging difficulties. J. Inherit. Metab. Dis. 24: 245-250.

8. Byers, S., Nuttall, J.D., Crawley, A.C., Hopwood, J.J., Smith, K., and Fazzalari, N.L. 1997. Effect of enzyme replacement therapy on bone formation in a feline model of mucopolysaccharidosis type VI. Bone 21: 425-431.
9. Sands, M.S., Vogler, C., Kyle, J.W., Grubb, J.H., Levy B, Galvin, N., Sly, W.S., and Birkenmeier, E.H. 1994. Enzyme replacement therapy for murine Mucopolysaccharidosis type VII. J. Clin. Invest. 93: 2324-2331.

10. Crawley, A.C., Brooks, D.A., Muller, V.J., Petersen, B.A., Isaac, E.L., Bielicki, J., King, B.M., Boulter, C.D., Moore, A.J., Fazzalari, N.L., Anson, D.S., Byers, S., and Hopwood, J.J. 1996. Enzyme replacement therapy in a feline model of Maroteaux-Lamy syndrome. J. Clin. Invest. 97: 1864-1873.

11. Simha, V., Zerwekh, J.E., Sakhaee, K., and Garg, A. 2002. Effect of subcutaneous leptin replacement therapy on bone metabolism in patients with generalized lipodystrophy. $J$. Clin. Endocrinol. Metab. 87: 4942-4945.

12. Horinouchi, K., Erlich, S., Perl, D.P., Ferlinz, K., Bisgaier, C.L., Sandhoff, K., Desnick, R.J., Stewart, C.L., and Schuchman, E.H. 1995. Acid sphingomyelinase deficient mice: a model of types A and B Niemann-Pick disease. Nat. Genet. 10: 288-293.

13. Jin, H.K., Carter, J.E., Huntley, G.W., and Schuchman, E.H. 2002. Intracerebral transplantation of mesenchymal stem cells into acid sphingomyelinase-deficient mice delays the onset of neurological abnormalities and extends their life span. J. Clin. Invest. 109: 1183-1191.

14. He, X., Chen, F., Dagan, A., Gatt, S., and Schuchman, E.H. 2003. A fluorescence-based, high-performance liquid chromatographic assay to determine acid sphingomyelinase activity and diagnose types A and B Niemann-Pick disease. Anal. Biochem. 314: 116-120.

15. Jin, H.K. and Schuchman, E.H. 2003. Ex vivo gene therapy using bone marrow-derived cells: combined effects of intracerebral and intravenous transplantation in a mouse model of Niemann-Pick disease. Mol. Ther. 8: 876-885.

16. Yamaji, A., Sekizawa, Y., Emoto, K., Sakuraba, H., Inoue, K., Kobayashi, H., and Umeda, M. 1998. Lysenin, a novel sphingomyelin-specific binding protein. J. Biol. Chem. 273: 5300-5306.

17. Miranda, S.P.R., Erlich, S., Friedrich, V.L., Gatt, S., and Schuchman, E.H. 2000. Infusion of recombinant human acid sphingomyelinase into Niemann-Pick disease mice leads to visceral, but not neurological, correction of the pathophysiology. FASEB J. 14: 1988-1995.

18. He, X., Miranda, S.P.R., Xiong, X., Dagan, A., Gatt, S., and Schuchman, E.H. 1999. Characterization of human acid sphingomyelinase purified from the media of overexpressing Chinese hamster ovary cells. Biochim. Biophys. Acta. 1432: 251-264. 